\title{
Analysis and Design of a Dual Band-Notched UWB Antenna Using Complementary Split Ring Resonator
}

\author{
A. Nacer, and N. Boukli-Hacene
}

\begin{abstract}
In this paper, the complementary split ring resonator (CSRR) is studied and applied to design a printed ultra wideband (UWB) antenna with dual band-notched characteristics. Dual band-notched function is obtained by incorporating the CSRR in the radiating element and the ground plane of the proposed UWB antenna. The designed antenna has a small size and operates over the frequency band from $3.2 \mathrm{GHz}$ to 13.5 GHz, with dual-band rejection at $3.5 \mathrm{GHz}$ (WiMAX band) and the other at 5-6 GHz (WLAN band). The antenna electromagnetic characteristics such as the $S(11)$ parameter, the radiation pattern and the gain are simulated using HFSS and CST. The obtained results are in good agreement and show that the proposed antenna can be used for UWB applications.
\end{abstract}

Index Terms-Metamaterials, complementary split ring resonator, antenna, UWB, notched band.

\section{INTRODUCTION}

In the latest years, ultra wide band (UWB) technology has become a highly competitive topic in both academy and industry communities of telecommunications. Compared with traditional technology, UWB systems offer important advantages such as high transmission rate, large capacity, low power and cost, etc. As an important component of the UWB system, UWB antenna has developed widely and rapidly since the authorization of the communication band (3.1-10.6 GHz) by the Federal communication commission in 2002 [1].

However, the frequency range for UWB systems will cause interference with existing narrowband wireless communication systems, for instance; the world interoperability for microwave access (WiMAX) operating in the $3.3-3.7 \mathrm{GHz}$ band, and the wireless local area network (WLAN) operating at $5.2 \mathrm{GHz}(5.15-5.35 \mathrm{GHz})$ and $5.8 \mathrm{GHz}$ $(5.725-5.825 \mathrm{GHz})$. To prevent the electromagnetic interference with the existing systems, many UWB antennas with band-notched characteristic are designed [2-8]; the simple and commonly used approach is to incorporate slots (U-shaped slots, I-shaped slots, L-shaped slots, etc.) [2-5], or parasitic strips in the radiating element of the antenna used as filters to reject these bands [6-8]. But most of the reported antennas are generally designed with only one notched band or

Manuscript received August 31, 2017; revised January 20, 2018. Date of publication March 15, 2018. Prof. Zoran Blažević has been coordinating the review of this manuscript and approved it for publication.

Authors are with the Telecommunication laboratory, Faculty of Technology, University of Tlemcen, Tlemcen, Algeria.

E-mails: nacerltt@gmail.com, bouklin@yahoo.com. Digital Object Identifier (DOI): 10.24138/jcomss.v14i1.403 two notched bands with coupling influence.Moreover, the notched band cannot be well controlled in terms of frequency selectivity.

To circumvent the above shortcomings, the complementary split ring resonator (CSRR) was used as a band rejection element. First, a CSRR is associated with a transmission line to study the effect of the geometrical parameters on the variation of the transmission zero frequency. This analysis is exploited and applied to design a novel compact UWB antenna with dual notch frequency bands. The rejection function can be controlled easily by adjusting the CSRR dimensions. The proposed antenna fully covers the UWB band and has an almost omnidirectional radiation over the entire operating band. The simulated results have been achieved using commercially available software package; high frequency structure simulator (HFSS) for parametric investigation and the authors try to validate the results by another software package, CST Microwave Studio, for the reason of not having access to the adequate laboratory equipment.

\section{ANALYSIS OF THE STOPBAND CHARACTERISTICS OF CSRR}

The waves that propagate throughout a negative permittivity medium are evanescent waves which make of this medium a good candidate for satisfying the above-mentioned purpose: rejecting frequency bands.

As the negative image of split ring resonators [9], complementary split ring resonators have been recently proposed and applied for the synthesis of transmission lines [10] (SRR and CSRR topologies are shown in Figure 1). It has been demonstrated that CSRR etched in the ground plane or in the conductor strip of planar transmission media (microstrip or $\mathrm{CPW}$ ) provide a negative effective permittivity to the structure and signal propagation is precluded (stopband behavior) in the vicinity of the resonant frequency [11].
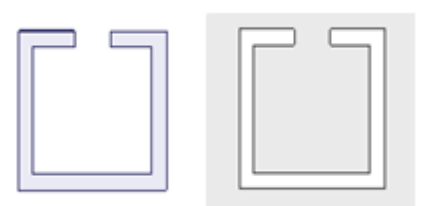

Fig. 1. Topology of the (a) Single SRR, (b) Single CSRR (Metal regions are depicted in gray). 
A rectangular CSRR associated with a transmission line is first studied to see the effect of geometrical parameters on the resonance frequency [10-12]. The structure of the CSRR with the transmission line is shown in Figure 2.

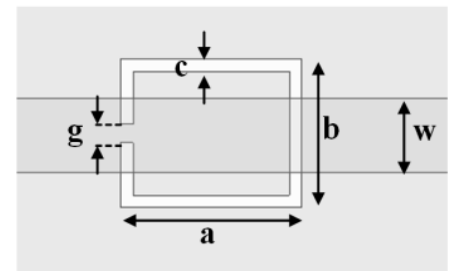

Fig. 2. The CSRR loaded microstrip line and its equivalent circuit model.

The transmission zero frequency $\left(\mathrm{f}_{\mathrm{Z}}\right)$ of the CSRR loaded microstrip line is defined as [12]:

$$
f_{Z}=1 / 2 \pi \sqrt{L_{c}\left(C_{c}+C\right)}
$$

where $\mathrm{C}$ is the coupling capacitance between the line and the CSRR, the CSRR is modeled by means of a parallel tank formed by the capacitance $\mathrm{C}_{\mathrm{c}}$ and the inductance $\mathrm{L}_{\mathrm{c}}$.

In this study, a transmission line of $50 \Omega$ characteristic impedance and a CSRR etched in the ground plane are deposited on the top and the bottom side of a FR4-epoxy substrate $\left(\varepsilon_{\mathrm{r}}=4.4\right.$, loss tangent of 0.02$)$ respectively.

In each simulation, the one parameter is varied while others are held constant. The initial CSRR dimensions are: $a=7 \mathrm{~mm}$, $\mathrm{b}=6 \mathrm{~mm}, \mathrm{c}=0.4 \mathrm{~mm}, \mathrm{~g}=0.4 \mathrm{~mm}$.

Figure 3 shows the simulated transmission coefficient of CSRR loaded microstrip line with different configurations.

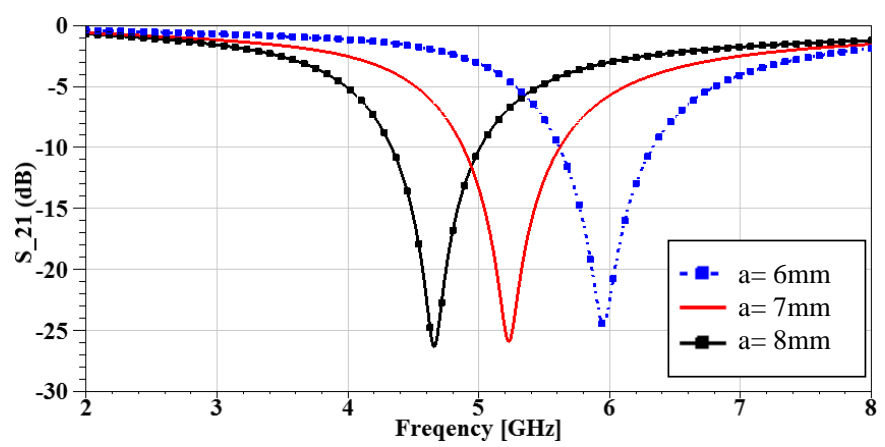

(a)

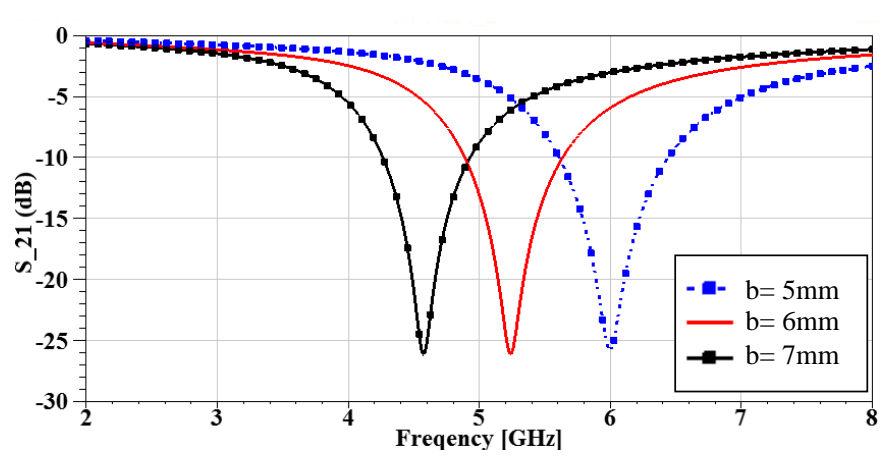

(b)

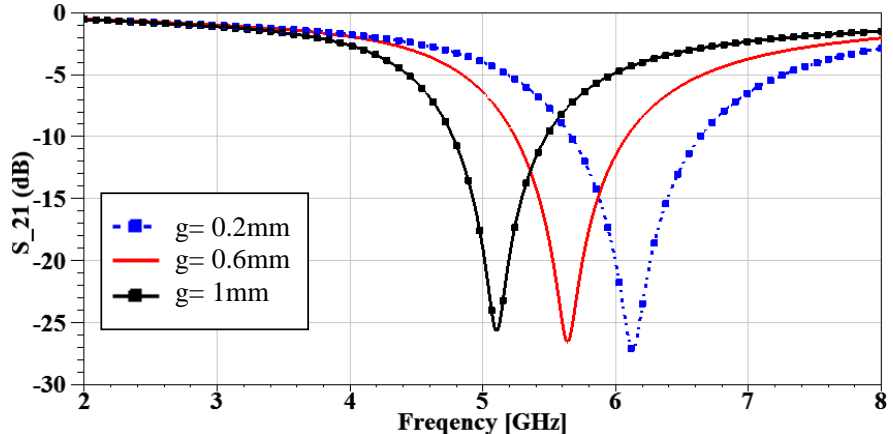

(c)

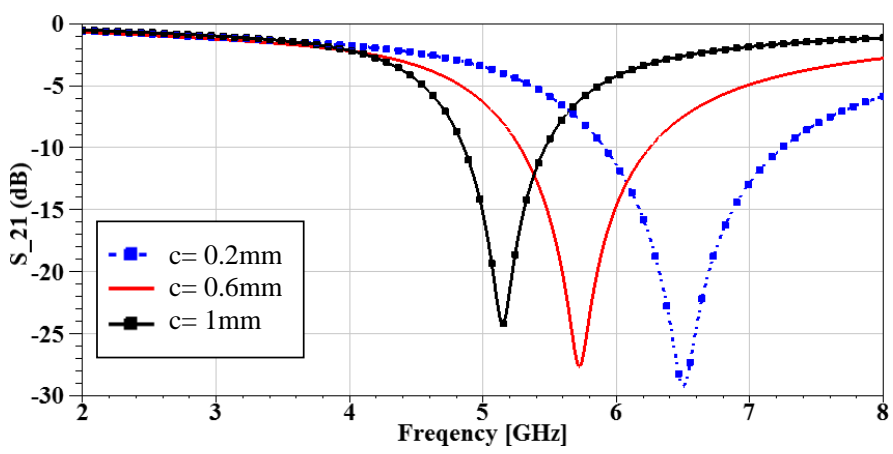

(d)

Fig. 3. Variation of the transmission coefficient (a) length (b) width (c) gap width (d) slot width simulated with HFSS

From the obtained results, the transmission zero frequency $\left(\mathrm{f}_{\mathrm{Z}}\right)$ varies clearly by varying the geometrical parameters $\mathrm{a}, \mathrm{b}$, c, w. It can be shown clearly from the equation (1), that the capacitance value $\mathrm{C}_{c}$ and the inductance $\mathrm{L}_{c}$ affects the frequency $f_{Z}$ (the inductance $L_{c}$ variation is neglected), while the larger CSRR (increasing length and width Figure 3(a), $3(b)$ ) corresponds to a larger capacitance (decreased $f_{Z}$ ). On the other hand, $f_{Z}$ increase in figure 3(c), 3(d) by increasing gap width and wire width, the decrease in capacitance $\mathrm{C}_{c}$ is induced by the fact that the larger space of $\mathrm{g}$ or $\mathrm{w}$ prevents the current to flow around the ring.

Table I summarizes the variation of the rejection frequency band based on geometric parameters.

TABLE I

FREQUENCY VARIATION $\left(\mathrm{F}_{\mathrm{Z}}\right.$ ) AS FUNCTION OF CSRR PARAMETERS

\begin{tabular}{|c|c|}
\hline Parameters & $f_{Z}$ \\
\hline$a \nearrow$ & $\searrow$ \\
\hline$b \nearrow$ & $\searrow$ \\
\hline$c \nearrow$ & $\nearrow$ \\
\hline$g \nearrow$ & $\nearrow$ \\
\hline
\end{tabular}

The same effect can be observed by etching CSRR in the transmission line with a slight variation of the transmission zero frequency.

\section{ANTENNA CONFIGURATION}

The antenna is printed on a FR4 epoxy substrate with a relative permittivity of 4.4 , a tangent loss of 0.02 , a size of $32 \times 28 \mathrm{~mm}^{2}$ and a thickness of $1.7 \mathrm{~mm}$. The radiating element and the feeding line are printed on the top side of the substrate, 
and a partial ground plane $\left(\mathrm{Lg} x(\mathrm{~W}-\mathrm{Wg}) \mathrm{mm}^{2}\right)$ is printed on the bottom side. For better matching, the top corners of the ground plane are rounded, by using a circle of radius $\mathrm{R}_{\mathrm{C}}=7 \mathrm{~mm}$, and a triangular slot (rounded with a circle of radius $2.2 \mathrm{~mm}$ ) is etched in the ground below feeding line. The width of the feed line is set at $2.8 \mathrm{~mm}$. Figure 4 shows the geometry of the proposed antenna.

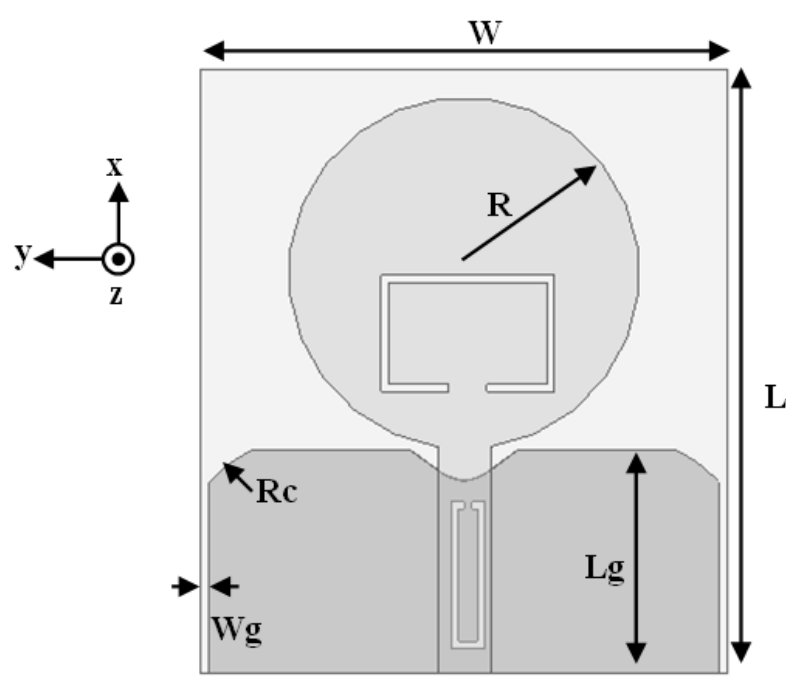

Fig. 4. The proposed Antenna with CSRR loading.

The optimized parameters of the proposed antenna are shown in Table II.

TABLE II

OPTIMIZED GEOMETRIC PARAMETERS OF THE ANTENNA

\begin{tabular}{|c|c|}
\hline Parameters & Value (mm) \\
\hline $\mathrm{L}$ & 32 \\
\hline $\mathrm{W}$ & 28 \\
\hline $\mathrm{R}$ & 9.3 \\
\hline $\mathrm{Lg}$ & 11.8 \\
\hline $\mathrm{Wg}$ & 0.5 \\
\hline $\mathrm{Rc}$ & 7 \\
\hline
\end{tabular}

The first band rejection is achieved by implementing the complementary Split ring resonator (CSRR) in the radiating element. The CSRR unit cell is designed to operate around $3.5 \mathrm{GHz}$. The geometry of the CSRR is as follows: $\mathrm{a} 1=6.2$ $\mathrm{mm}, \mathrm{b} 1=9.2 \mathrm{~mm}, \mathrm{c} 1=1.1 \mathrm{~mm}, \mathrm{~g} 1=2 \mathrm{~mm}$.

To achieve the second frequency notch-band $(5 \mathrm{GHz}-6$ $\mathrm{GHz}$ ), The Complementary split ring resonator (CSRR) is loaded in the ground plane. The CSRR dimensions are: $\mathrm{a} 2=7.8$ $\mathrm{mm}, \mathrm{b} 2=1.8 \mathrm{~mm}, \mathrm{c} 2=0.8 \mathrm{~mm}, \mathrm{~g} 2=0.8 \mathrm{~mm}$.

\section{Simulation And Results}

The proposed antenna was simulated using two software package CST and HFSS. The simulated S (11) of the proposed antenna is depicted in the Figure.5. The $S$ (11) parameter of the antenna without CSRR is also plotted for comparison, it can be observed that the antenna without CSRR and with CSRR operates from $3.2 \mathrm{GHz}$ to $13.48 \mathrm{GHz}$ for $\mathrm{S}$ (11) less than $-10 \mathrm{~dB}$, it covers the band assigned for UWB application.
From the figure it is very clear that the desired filtering property is achieved by introducing two CSRR, the two notched bands are $3.20-3.68 \mathrm{GHz}$ and $4.86-6.09 \mathrm{GHz}$ with CST and $3.34-3.94 \mathrm{GHz}$ and $5.02-5.84 \mathrm{GHz}$ with HFSS. The obtained results show a good agreement between simulation results.

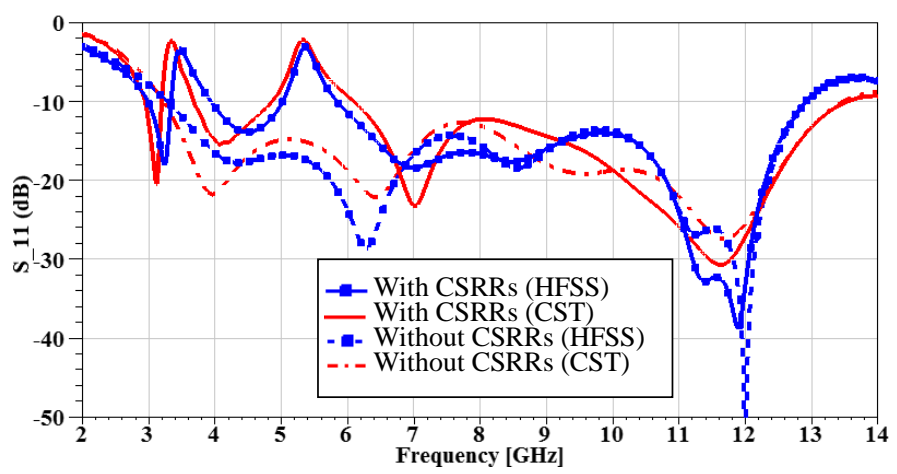

Fig. 5. S (11) parameter of the proposed dual band notched antenna and the reference antenna.

The UWB antenna with dual band notched using CSRRs has been analyzed with a parametric study. The parametric analysis is executed in order to review the effects of CSRRs parameters. All the parameters are kept constant in the simulation with the exception of the selected parameter.

Figure 6 shows the tuning effect by length, width and gap width on the rejection band $3.5 \mathrm{GHz}$, while figure 7 illustrates the effect of varying the length, the width and the slot width on the rejection band $5-6 \mathrm{GHz}$. As mentioned earlier, with adjustment of the aforementioned parameters, the rejection bands of each CSRR can be adjusted at the desired value.

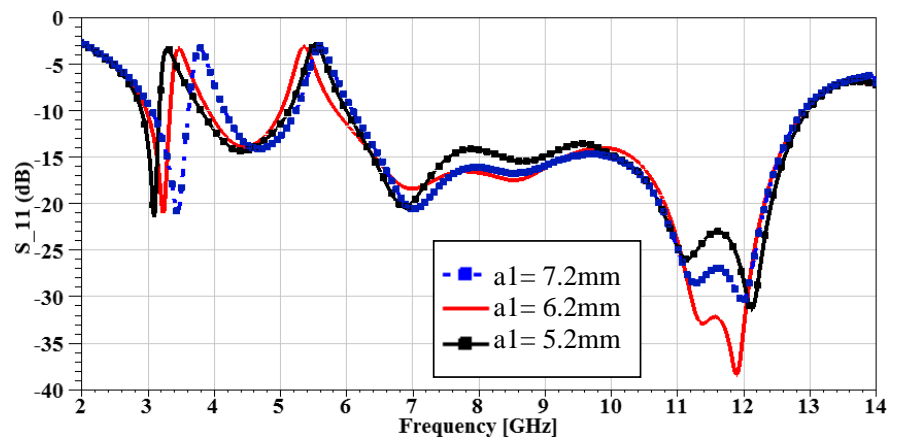

(a)

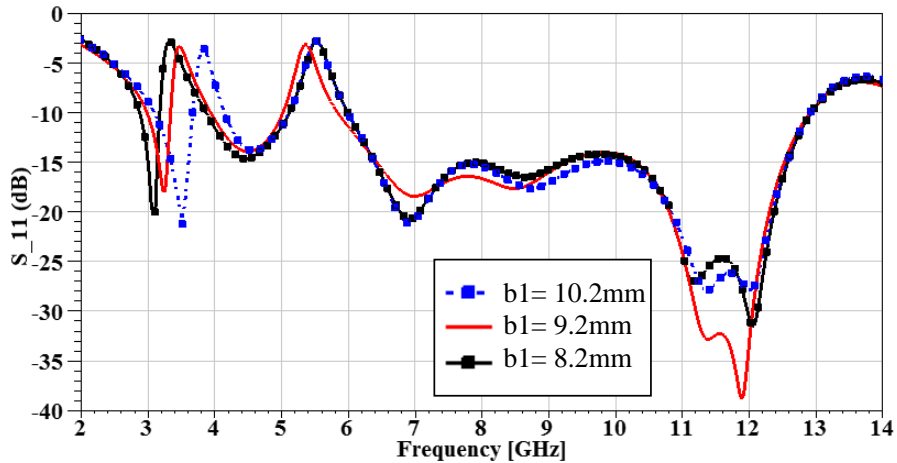

(b) 


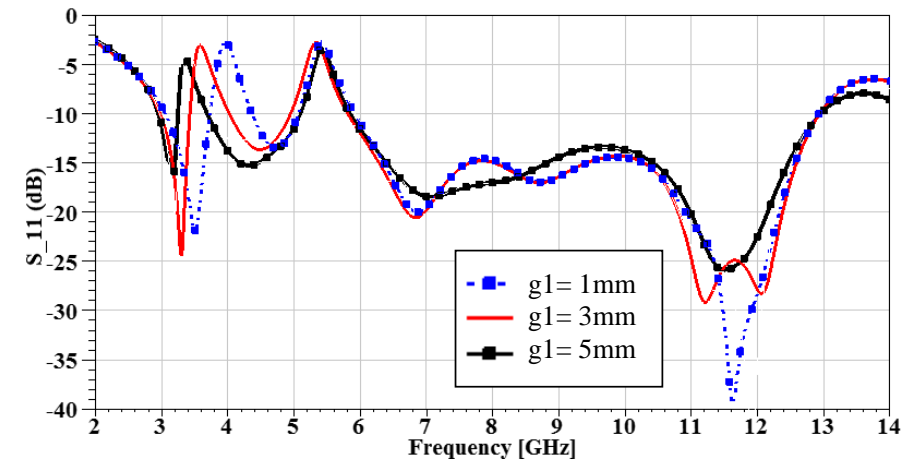

(c)

Fig. 6. S (11) parameter for various : (a) length a1, (b) width bland (c) gap width g1, simulated with HFSS.

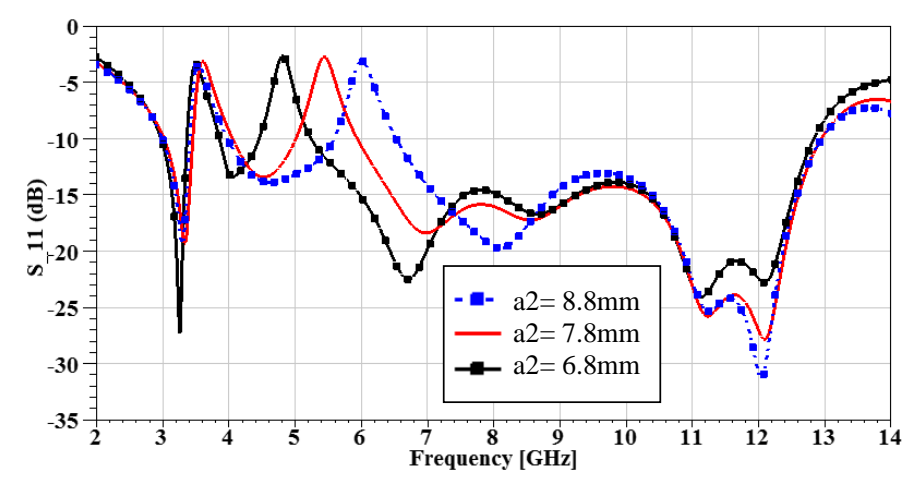

(a)

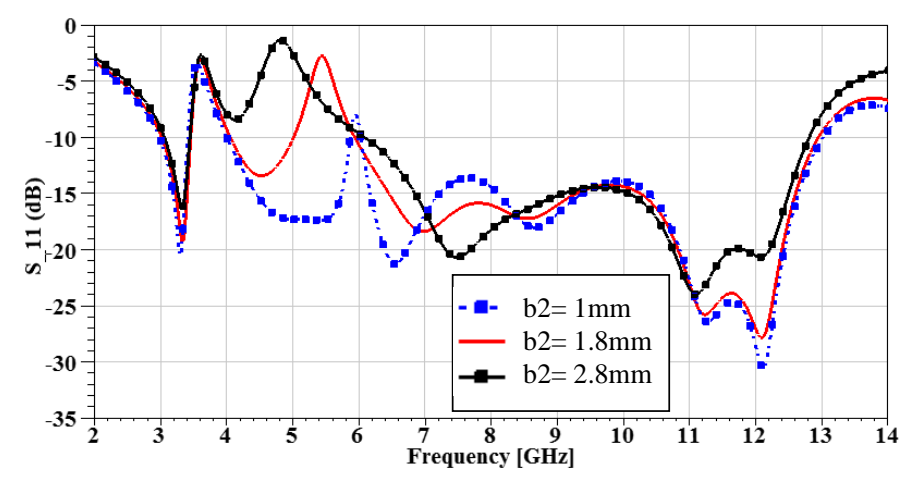

(b)

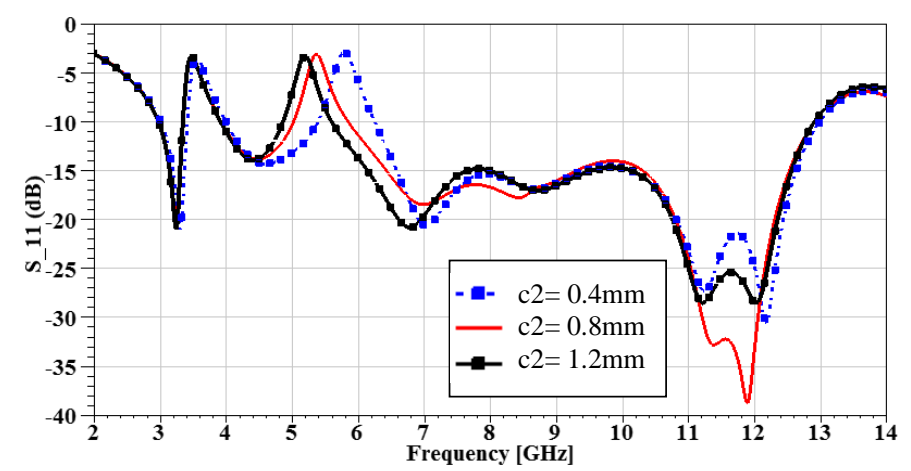

(c)

Fig. 7. S (11) parameter for various : (a) length a1, (b) width bland (c)slot width c1, simulated with HFSS.

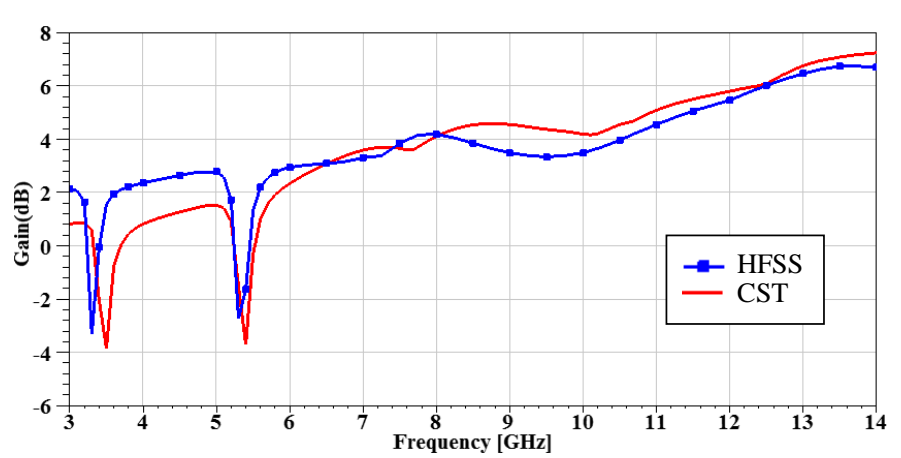

Fig. 8. Gain of the dual band notched antenna.

Figure 8 indicates the simulated gain. The gain drops swiftly in the region of the rejection band; which clearly indicates the filtering effect of CSRRs. The antenna discloses relatively stable gain except for the unwanted bands.

Figures 9 and 10 illustrate the radiation patterns of the proposed antenna at the pass band frequencies; 4, 8, and 12 $\mathrm{GHz}$.

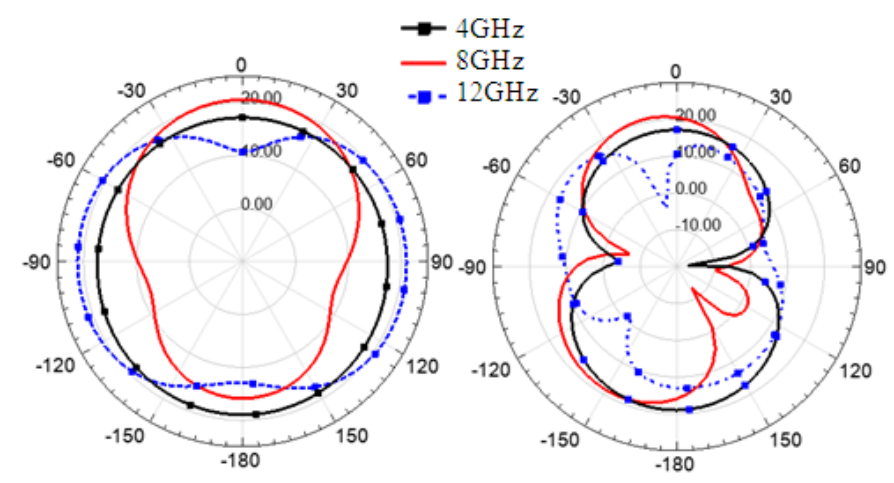

(a)

(b)

Fig. 9. Radiation pattern : (a) H-plane (b) E-plane simulated with HFSS.

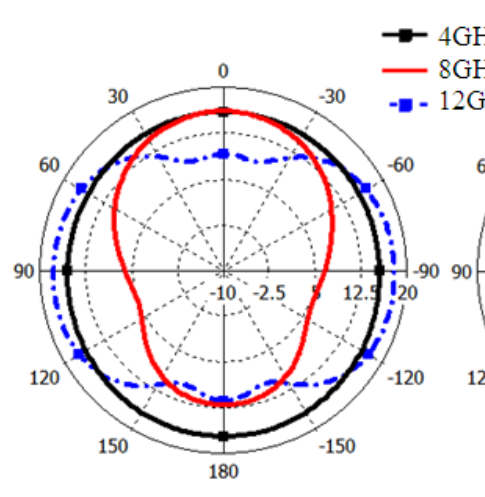

(a)

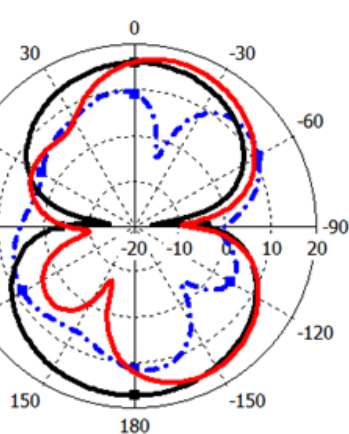

(b)
Fig. 10. Radiation pattern: (a) H-plane (b) E-plane simulated with CST.

It can be seen that a dipole radiation pattern in the E-plane and a nearly omnidirectional radiation in H-plane. 


\section{CONCLUSION}

In this paper, the frequency selective properties of the CSRR cell show a considerable relation with its geometric parameters, which have been analyzed. As application, a printed UWB antenna with dual band notched characteristic is proposed and analyzed. The two stop bands are generated by etching CSRRs in the radiating element and ground plane. The geometric parameters of CSRRs are chosen to eliminate interference with the WiMAX / WLAN systems. The proposed antenna covers the entire UWB frequency band and has good radiation performance. In addition, it has a simple structure and can be manufactured easily, which makes it a good candidate for UWB applications.

\section{REFERENCES}

[1] FCC, "First report and order on ultra-wideband technology," Washington, DC, Apr. 2002.

[2] S.W. Su, K.L. Wong, and C.L. Tang, "Band-notched ultra-wideband planar-monopole antenna," Microwave Opt. Technol. Lett., vol. 44,no.3,pp. 217-219, Feb. 2005.

[3] Nakchung Choi, Changwon Jung, Joonho Byun, Frances J Harackiewicz, "Compact UWB Antenna with I-Shaped Band-Notch Parasitic Element for Laptop Applications," IEEE Antennas Wireless Propag. Lett, vol. 8, pp. 580-582, Apr. 2009.

[4] Z Cui, Y - C Jiao, Li Zhang and F -S Zhang, " The band-notch function for a printed ultra-wideband monopole antenna with E-shaped slot," Microwave Opt. Technol. Lett., vol. 50, no.8, pp.2048-2052, May 2008.

[5] H.-J. Zhou, B.-H. Sun, Q.-Z. Liu and J.-Y. Deng, "Implementation and investigation of U-shaped aperture UWB antenna with dual band notched characteristics," Electron. Lett., vol. 44, no. 24, pp. 1387-1388, Dec. 2008.

[6] J. Ma, Y.-Z. Yin, J.-Y. Deng, and Q. Ma, "Design of an ultra-wideband antenna with a novel dual band-notched structure," Microwave Opt. Technol. Lett., vol. 51, no. 3, pp. 814-817, Mar. 2009.

[7] M. Abbosh and M. E. Bialkowski, "Design of UWB planar bandnotched antenna using parasitic elements," IEEE Trans. Antennas Propagat., vol. 57, no. 3, pp. 796-799, Mar. 2009.

[8] Jin-Xiang Xiao, Mei-Fang Wang, and Guo-Jian Li, "Double-printed rectangular patch dipole antenna with band-notch function for UWB communications," Microwave Opt. Technol. Lett., vol. 52, no. 2, pp.269-272, Mar. 2010.

[9] Pendry, J. B., A. J. Holden, D. J. Robbins, and W. J. Stewart, "Magnetism from conductors and enhanced nonlinear phenomena," IEEE Trans. Microw. Theory Tech., vol. 47, no. 11, pp.2075-2084, Nov. 1999.

[10] Falcone, F., T. Lopetegi, J. D. Baena, R. Marques, F. Martin, and M Sorolla, "Effective negative- $\varepsilon$ stop-band microstrip lines based on complementary split ring resonators," IEEE Microw. Wireless Compon. Lett., vol. 14, no. 6, pp. 280-282, Jul. 2004.

[11] Bonache, J., Member, S., Gil, I., Member, S., \& García-garcía, J. "Novel Microstrip Bandpass Filters Based on Complementary Split-Ring Resonators," IEEE Trans. Microw. Theory Tech., vol. 54, no. 1, pp. 265-271, Jan. 2006

[12] Baena, J. D., J. Bonache, F. Martin, and F. Falcone, "Equivalent circuit models for split ring resonators and complementary split ring resonators coupled to planar transmission lines," IEEE Trans. Microw. Theory Tech., vol. 53, no. 4, pp.1451-1460, Apr. 2005.

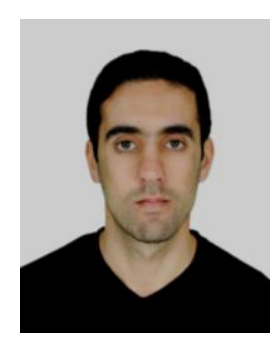

Abdelghani Nacer was born in Tlemcen, Algeria, in 1986. He received both of his engineering degree and Magister degree in telecommunication engineering from Abou Bekr Belkaid University in Tlemcen, Algeria, in 2009 and 2012, respectively.

$\mathrm{He}$ is currently pursuing the Ph.D degree in telecommunication engineering at the same university.

Since 2012 , he joined the telecommunication laboratory as doctoral researcher at Tlemcen University, Algeria. His research interests include microstrip antennas, microwave circuits and metamaterials.

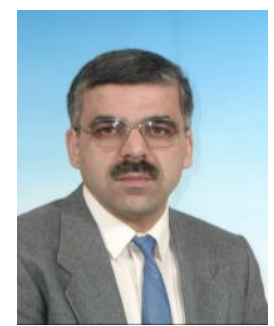

Noureddine Boukli-Hacene was born in 1959 in Tlemcen, Algeria. He received his Doctorate Degree (prepared at the "Centre National d'Etudes Spatiales" in Toulouse, France), in electrical engineering from University of Limoges, France, in 1985. Then he joined the University of Tlemcen. Actually, he is a Professor in electrical engineering at the same university. His research interests include, among others, microstrip and miniaturized antennas and microwave circuits. 